\title{
Placental Laterality as a Predictor for Development of Pre-Eclampsia
}

\author{
Arjumand Bano ${ }^{1}$, Nimma Yogitha Reddy² \\ ${ }^{1}$ Senior Resident, Department of Obstetrics and Gynaecology, Chalmeda Anand Rao Institute of Medical Sciences,

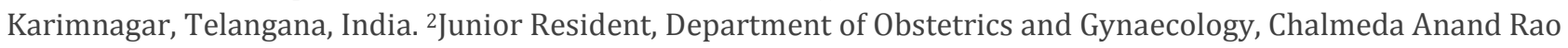 \\ Institute of Medical Sciences, Karimnagar, Telangana, India.
}

ABSTRACT

\section{BACKGROUND}

Hypertensive disorders complicate 5 to 10 percent of all pregnancies; Pre-eclampsia syndrome, either alone or superimposed on chronic hypertension, is the most dangerous. $16 \%$ of maternal deaths were reported due to hypertensive disorders in developed countries according to WHO. The basic classification is of 4 types: Gestational hypertension, pre-eclampsia and eclampsia syndrome, chronic hypertension, pre-eclampsia superimposed on chronic hypertension. Gestational hypertension- blood pressure of $>140 / 90 \mathrm{mmHg}$ without proteinuria, developing after 20 weeks of gestation in a previously normotensive woman. Pre-eclampsia is a multisystem disorder of unknown aetiology is characterised by blood pressure of $>140 / 90 \mathrm{mmHg}$ with proteinuria after 20 weeks of gestation in a previously normotensive and nonproteinuric woman. Eclampsia is pre-eclampsia complicated with grand mal seizures and/or coma. Chronic hypertension is known hypertension before pregnancy or hypertension diagnosed first time before 20 weeks of pregnancy.

\section{METHODS}

This is a prospective observational study carried out in the department of obstetrics and gynaecology of Chalmeda Anand Rao Institute of Medical Sciences, Karimnagar. The study period was two years from January 2017 to March 2019. A total of 50 singleton pregnant women were included in the study to evaluate relationship between placental location and occurrence of pre-eclampsia and to find out whether placental laterality as determined by ultrasound can be used as a predictor of development of pre-eclampsia. To evaluate relationship between placental location and occurrence of pre-eclampsia, incidence of pre-eclampsia in patients with centrally and laterally located placenta was studied to find out as to whether placental laterality as determined by ultrasound can be used as a predictor of development of pre-eclampsia.

\section{RESULTS}

The incidence of pre-eclampsia was 14 in 50 singleton pregnancies. The maximum number of pre-eclampsia occurred between 21-25 years and was more common in primigravida (49\%) than in second and multigravida. Out of $49 \%$ primigravida, $11 \%$ had lateral placenta and $38 \%$ had central placenta. Out of $11 \%$ lateral placenta $7 \%$ developed severe pre-eclampsia. Incidence of complications of pre-eclampsia like IUGR and low APGAR score were also more when pre-eclampsia has developed with a laterally implanted placenta compared to central placenta. All these show evidence of existence of significant association between placental laterality and presence of pre-eclampsia, intra uterine growth restriction or both.

\section{CONCLUSIONS}

Ultrasonography is simple, non-invasive, easy to perform, cost effective, diagnostic method to identify high risk cases. Females with laterally located placenta have a five times greater risk of developing pre-eclampsia. So, these pregnancies may require careful obstetric management to achieve a more favourable outcome and decrease the maternal and perinatal morbidity associated with pre-eclampsia

\section{KEY WORDS}

Placenta, Placental Laterality, Placental Position, Pre-Eclampsia, Ultrasound

\author{
Corresponding Author: \\ Dr. Arjumand Bano, \\ Senior Resident, \\ Department of Obstetrics and Gynaecology, \\ Chalmeda Anand Rao Institute of Medical \\ Sciences, Karimnagar, Telangana, India. \\ E-mail: arju2574@gmail.com
}

DOI: $10.14260 /$ jemds/2019/592

Financial or Other Competing Interests: None.

How to Cite This Article:

Bano A, Reddy NY. Placental laterality as a predictor for development of preeclampsia. J. Evolution Med. Dent. Sci. 2019;8(35):2729-2732, 10.14260/jemds/2019/592

Submission 17-04-2019,

Peer Review 12-08-2019,

Acceptance 20-08-2019,

Published 02-09-2019. 


\section{BACKGROUND}

Hypertensive disorders complicate 5 to 10 percent of all pregnancies; and together they are one member of the deadly traid ${ }^{1}$ along with haemorrhage and infection that contributes greatly to maternal morbidity and mortality. Pre-eclampsia syndrome, either alone or superimposed on chronic hypertension, is the most dangerous. $16 \%$ of maternal deaths were reported due to hypertensive disorders in developed countries according to $\mathrm{WHO}^{2}$. Quality antenatal care, early diagnosis of hypertensive disorders and a high index of suspicion is the key to early diagnosis of complications and timely intervention. The basic classification is of 4 types:Gestational hypertension- blood pressure of $>140 / 90 \mathrm{mmHg}$ without proteinuria, developing after 20 weeks of gestation in a previously normotensive women pre-eclampsiaMultisystem disorder of unknown aetiology characterised by blood pressure of $>140 / 90 \mathrm{mmHg}$ with proteinuria after 20 weeks of gestation in a previously normotensive and nonproteinuric woman eclampsia-women with preeclampsia complicated with grand mal seizures and/or coma chronic hypertension-known hypertension before pregnancy or hypertension diagnosed first time before 20 weeks of pregnancy pre-eclampsia superimposed on chronic hypertension. Pre-eclampsia is a complex clinical syndrome involving multiple organ systems and still remains the principal cause of maternal and perinatal mortality and morbidity.

HELLP syndrome: severe form of preeclampsia characterised by haemolysis, abnormal peripheral blood smear, bilirubin $>1.2 \mathrm{mg} / \mathrm{dl})$, thrombocytopenia $\left(<100,000 / \mathrm{mm}^{3}\right)$ and elevated liver enzymes (AST $>70 \mathrm{IU} / \mathrm{L}$, LDH $>600 \mathrm{U} / \mathrm{L}$ ) Prediction of pre-eclampsia using clinical risk factors:- primiparity, previous pre eclamptic pregnancy, chronic hypertension, history of thrombophilia, multifetal pregnancy, invitro fertilization, family history of preeclampsia, type 1 diabetes or type 2 diabetes mellitus, obesity. ${ }^{3}$ Pathogenesis involves vasospasm, endothelial cell injury, increased pressor responses, prostaglandins, nitric oxide, endothelins, angiogenic and antiangiogenic proteins. ${ }^{4,5}$

Measurement during early pregnancy-or across pregnancy- of various biological, biochemical and biophysical markers implicated in pre-eclampsia syndrome pathophysiology has been proposed to predict its development. Attempts have been made to identify early markers of faulty placentation, impaired placental perfusion, endothelial cell activation and dysfunction and these have resulted in testing activation of coagulation. ${ }^{6}$ For the most, strategies with poor sensitivity and with poor positivepredictive value for pre-eclampsia (Conde-Agudelo, 2014, Lindheimer, 2008b, Odibo, 2013).4'56. Currently, no screening tests are predictably reliable, valid, and economical (Kleinrouwefer, 2012) There are, however, combinations of tests, some yet to be adequately evaluated, that may be promising (Dugoff, 2013; 2011'Navaratnam, 2013; Olsen, 2012).A number of studies have shown that location of placenta may influence the uterine blood flow distribution and predispose the pregnancy to an adverse outcome like PIH. In the past two decades ultrasonography has proved to the safest, easiest, and most accurate method for assessing placental laterality ${ }^{7}$ the non-invasive studies in second trimester of pregnancy revealed defective uterine perfusion in laterally implanted placenta. Pre-eclampsia occurs only in the presence of chorionic viili. It has been shown that in humans both uterine arteries have a significant number of branches and that each supply the corresponding side of the uterus. Although that each supply the corresponding side of the uterus, anastomoses between the two uterine arteries exist, there is no proof that these are functional ${ }^{8}$. When the placenta is laterally located, the uterine artery closer to the placenta has lower resistance than the one opposite to it. In patients with centrally located placentas both uterine arteries demonstrated similar resistance ${ }^{1}$. When the placenta is centrally located, the uteroplacental blood flow needs are met by equal contribution from both uterine arteries. However, when the placenta is laterally located, in the majority of cases the utero-placental blood flow needs are met primarily by one of the uterine arteries with same contribution from the other uterine artery via the collateral circulation. ${ }^{9}$ The degree of collateral circulation may not be the same in all patients and deficient contribution may facilitate the development of pre-eclampsia, intrauterine growth restriction or both the cytotrophoblasts fail to adopt a vascular adhesion phenotype in pre-eclampsia. This may explain the reduced trophoblastic invasion in laterally situated placenta when the uteroplacental blood flow needs are mainly met by one side uterine artery. Prediction of pre-eclampsia using clinical risk factors:-primiparity, previous pre eclamptic pregnancy, chronic hypertension, history of thrombophilia, multifetal pregnancy, invitro fertilization, family history of preeclampsia, type 1 diabetes or type 2 diabetes mellitus, obesity. 6,10

We wanted to evaluate relationship between placental location an occurrence of pre-eclampsia, incidence of preeclampsia in patients with centrally and laterally located placenta, find out whether placental laterality determined by ultrasound can be used as a predictor of development of preeclampsia. ${ }^{11}$

\section{METHODS}

The prospective observational study with the consent from the ethical clearance committee of Chalmeda Anand Rao institute of medical sciences, Karimnagar the study has been carried out in the department of obstetrics and gynaecology which is a prospective study. The study was carried out by taking the informed consent from the patient. The study period is two years from JANUARY 2017 TO MARCH 2019. A total of 50 singleton pregnant women is undertaken to evaluate relationship between placental location and occurrence of pre-eclampsia and to find out whether placental laterality as determined by ultrasound can be used as a predictor of development of pre-eclampsia.9,10

\section{Sampling Technique}

Convenience sampling.

\section{Diagnostic Criteria}

Based on the location of placenta.

\section{Inclusion Criteria}

All primigravida and multigravida with singleton pregnancy. Diagnosis and classification of hypertensive disorders is 
according to the criteria by the working group of national high blood pressure education programme (2000).12 The location of placenta is determined around 18-24 weeks of gestational age, The placenta is classified as central when it is equally distributed between the right and left side of the uterus irrespective of anterior, posterior and fundal position. When $75 \%$ or more of the placental mass is to one side of the midline, it is classified as unilateral right or left placenta.8,7

\section{Exclusion Criteria}

Multiple gestation, chronic hypertensive patients, renal diseases, uterine anomalies, diabetes previous history of preeclampsia and eclampsia history of smoking IUD, documented major congenital anomalies, collagen vascular diseases, patients who are not willing for follow up.

\section{Statistical Tool}

SPSS Software.

\section{RESULTS}

Out of 50 patients who were included in this study 13 had lateral placenta and 37 had central placenta-Đistribution of cases according to development of pre-eclampsia Incidence of pre-eclampsia is around $7 \% \cdot{ }^{13}$

\section{Distribution of Cases According to Parity}

Out of 50 patients $30 \%$ were primi, $13 \%$ were second gravida and $7 \%$ were multi gravida.

\section{Distribution of Cases According to Age}

Out of 50 patients 5 were of age 20 and $<20,26$ were around 21-25 years, 15 were of age 26-30 years, 4 were of $31-35$ years of age.

\begin{tabular}{|c|c|c|c|}
\hline & Primigravida & Second & Multi \\
\hline Lateral & 6 & 4 & 4 \\
\hline Central & 19 & 14 & 3 \\
\hline \multicolumn{3}{|c|}{ Table 1. Relation between Parity and Location Placenta } \\
\hline
\end{tabular}

\begin{tabular}{|c|c|c|}
\hline Parity & Mild Pre-Eclampsia & Severe Pre-Eclampsia \\
\hline Primi gravid & $3(33.3)$ & $6(66.6)$ \\
\hline Second gravid & $2(66.6)$ & $1(33.3)$ \\
\hline Multi gravid & $1(50 \%)$ & $1(50 \%)$ \\
\hline \multicolumn{2}{|c|}{ Table 2. Relation between Parity and Severity of Preeclampsia } \\
\hline
\end{tabular}

\begin{tabular}{|c|c|c|}
\hline APGAR (4-6) & APGAR (6-8) & APGAR (8-10) \\
\hline $2(14.3 \%)$ & $5(35.7 \%)$ & $7(50.0 \%)$ \\
\hline \multicolumn{3}{|c|}{ Table 3. Neonatal Outcome Based on APGAR Scores in Patients } \\
with Lateral Placenta \\
\hline
\end{tabular}

\begin{tabular}{|c|c|c|}
\hline APGAR (4_6) & APGAR (6-8) & APGAR (8-10) \\
\hline $1(2.8 \%)$ & $5(13.9 \%)$ & $30(83.3)$ \\
\hline \multicolumn{2}{|c|}{ Table 4. Neonatal Outcome Based on Apgar Score in Patients } \\
with Central Placenta \\
\hline
\end{tabular}

\begin{tabular}{|c|c|c|c|}
\hline Mode of Delivery & Primi & Second & Multi \\
\hline Vaginal & $2(14.3)$ & $1(7.1)$ & $3(21.4)$ \\
\hline Caesarean & $4(28.6)$ & $3(21.4)$ & $1(7.21)$ \\
\hline \multicolumn{4}{|c|}{ Table 5. Analysis of Mode of Delivery in Patients with Central Placenta } \\
\hline
\end{tabular}

\begin{tabular}{|c|c|c|c|}
\hline Mode of Delivery & Primi & Second & Multi \\
\hline Vaginal & $11(31.5)$ & $11(31.5)$ & $3(8.2)$ \\
\hline Caesarean & $7(20.5)$ & $3(8.2)$ & $0(0)$ \\
\hline \multicolumn{3}{|c|}{ Table 6. Mode of Delivery in Patients with Central Placenta } \\
\hline
\end{tabular}

\begin{tabular}{|c|c|c|c|}
\hline $\begin{array}{c}\text { Position of } \\
\text { Placenta }\end{array}$ & Primigravida $^{\mathbf{1 0}}$ & Second Gravida $^{\mathbf{4}}$ & Multigravida $^{\mathbf{1 2}}$ \\
\hline Central & $2(22.22 \%)$ & $1(33.33)$ & $0(0 \%)$ \\
\hline Lateral & $7(77.78 \%)$ & $2(66.67 \%)$ & $2(100 \%)$ \\
\hline Total & $\mathbf{9 ( 6 4 . 2 8} \%)$ & $\mathbf{3 ( 2 1 . 4 2 \% )}$ & $\mathbf{2 ( 1 4 . 2 8 \% )}$ \\
\hline \multicolumn{3}{|c|}{ Table 7. Relation between Parity, Location of Placenta } \\
\hline
\end{tabular}

\begin{tabular}{|c|c|c|c|}
\hline $\begin{array}{c}\text { Primigravida } \\
\mathbf{2}(\mathbf{6 6 . 6 6 \% )}\end{array}$ & $\begin{array}{c}\text { Second Gravida } \\
\mathbf{1}(33.33 \%)\end{array}$ & \\
\hline Central placenta & Lateral placenta & Central placenta & Lateral placenta \\
\hline 0 & $2(100 \%)$ & 0 & $1(100 \%)$ \\
\hline \multicolumn{3}{|c|}{ Table 8. Relation between Parity, Location of Placenta and } \\
Complication of Pre-Eclampsia like IUGR \\
\hline
\end{tabular}

Out of 36 patients with central placenta, 26(71\%) patients delivered by vaginal route $10(29 \%)$ patients underwent caesarean section.

\section{DISCUSSION}

Pre-eclampsia is a complex clinical syndrome involving multiple organ systems and still remains the principal cause of maternal and perinatal mortality and morbidity. The search for an ideal predictive and preventive measure remains challenging. ${ }^{14}$ The source of blood supply for the placenta are the two uterine arteries there is poor evidence of efficient functional collateral anastomosis between the two uterine vessels, so in a centrally located placenta, the blood flow will be abundant from both uterine arteries, but a laterally implanted placenta (Which is diagnosed if $75 \%$ or more is to one side of the uterine cavity) gets its blood supply from one uterine artery which is insufficient for adequate placental perfusion this causes predisposition to uteroplacental insufficiency and IUGR. A deficient perfusion of the placenta will impede proper trophoblastic invasion of spiral arterioles which is primary inciting factor in development of pre-eclampsia. ${ }^{15}$ The present study shows increased incidence of pre-eclampsia, intra uterine growth restriction and relatively poorer neonatal outcome in patients with lateral placenta which is statistically significant and correlates well with previous studies. ${ }^{11}$

The pathophysiological characteristics of pre-eclampsia are complex, and the cause remains unknown. One of the fundamentals disturbances in patients with this condition is decreased uteroplacental blood flow. However, whether this is the cause or result yet to be discussed. Our data indicate that the presence of lateral is strongly associated with preeclampsia. The present study shows that the location of placenta in primigravidae, second gravidae and multi gravidae may predict the development of pre-eclampsia, IUGR and its complications to a considerable extent and may be used as simple, non-expensive, easily accessible and reproducible screening test for the prediction of preeclampsia and IUGR.16 Further studies are necessary to evaluate the sensitivity of placental laterality is a predictor of the development of pre-eclampsia. As yet there is no practical, acceptable and reliable screening test for preeclampsia that has been thoroughly tried and tested. In the present study placental laterality has a sensitivity of $78.57 \%$ which though low is much better than most other tests. Besides, it has a very good specificity of $81.39 \%$ and negative predictive value of $95.89 \%$. Its positive predictive value is low but so is the case with most other tests. It is a very useful 
cost effective and easy to perform non-invasive test. Present study correlates well with the study conducted by Dr. Muralidhar Pai and the study conducted by Dr. Kofinas. Incidence of lateral placenta is around $13 \%$ in the present study out of 50 patients which correlates well with the studies of Pai MV Pillai J et al 2005, Bhalerao AV et al 2013, Rajeshwari Pillay et al. Out of 50 patients 7 patients developed pre-eclampsia this is comparable with SJ Kore et al 2016, Pai MV Pillai J et al 2005, Bhalerao AV et al 2013, Preety et al, Chinnappa et al, Parul S Jani et al. In present study out of 13 patients with lateral placenta, 7 patients developed pre-eclampsia. Incidence is around $14 \%$ which is comparable with the previous studies Preveena Fareed et al, Bhalerao AV et al 2013, Patel A et al 2012, Parul S Jani et al. Present study out of 50, 37 patients had central placenta, well comparable to previous studies PAI MV PILLAI J et al 2005, Bhalerao AV et al 2013, Rajeshwari Pillay et al 2015. Present study out of 37 patients with central placenta 3 patients developed pre-eclampsia incidence is $4.1 \%$ which is comparable with previous studies PAI MV PILLAI J et al 2005, Bhalerao AV et al 2013, Preety et al, Chinnappa et al.

\section{CONCLUSIONS}

In case of unilateral placenta, the absence or insufficient trophoblastic invasion of arteries on contralateral side would make them retain their sensitivity to vasoactive substance during pregnancy. Ultrasonography is simple, non-invasive, easy to perform, cost effective, diagnostic method to identify high risk cases. From the above study, it is concluded that laterally located placenta on ultrasound done at 18-24 weeks is associated with increased risk of development of preeclampsia. Females with laterally located placenta have a five times greater risk of developing pre-eclampsia so these pregnancies may require careful obstetric management to achieve a more favourable outcome and decrease the maternal and perinatal morbidity associated with preeclampsia.

\section{REFERENCES}

[1] Aggarwal P, Kangjam P, Terhase N. Study on relation between placental laterality in second trimester ultrasound and development of pre-eclampsia at term. Journal of Evolution of Medical and Dental Sciences 2015;4(104):16926-8.

[2] Lindheimer MD, Taylor RN, Cunningham FG, et al. Introduction, history, controversies and definitions. In: Taylor RN, Roberts JM, Cunningham FG, eds. Chesley's hypertensive disorders in pregnancy. $4^{\text {th }}$ edn. Amsterdam, Academic Press 2014.

[3] American College of Obstetricians and Gynaecologists, Task Force on Hypertension in pregnancy. Hypertension in pregnancy. Report of the American College of Obstetricians and Gynecologists' Task Force on Hypertension in pregnancy. Obstet Gynecol 2013;122(5):1122-31.

[4] Odibo AO, Rada CC, Cahill AG, et al. First trimester serum soluble fms; like tyrosine kinase-1, free vascular endothelial growth factor, placental growth factor and uterine artery Doppler in pre eclampsia. J Perinatal 2013;33(9):670-4.

[5] Haggerty CL, Seifert ME, Tang G, et al. Second trimester anti-angiogenic proteins and preeclampsia. Pregnancy Hypertens 2012;2(2):158-63.

[6] Erlebacher A. Immunology of the maternal-fetal interface. Annu Rev Immunol 2013;31:387-411.

[7] Muralidharan PV, Jyothi P. Placental laterality by ultrasound - a simple yet reliable predictive test for preeclampsia. J Obstet Gynecol India 2005;55(5):431-3.

[8] Oslen RN, Wolkers D, Dunsmoor-Su R, et al. Abnormal second-trimester serum analytes are more predictive of preterm preeclampsia. Am J Obstet Gynecol 2012;207(3):228.e1-7.

[9] Kakkar T, Singh V, Razdan R, et al. Placental laterality as a predictor for development of preeclampsia. J Obstet \& Gynecol India 2013;63(1):22-5.

[10] Fareed P, Mahajan N, Siraj F. Placental laterality detected by USG as predictor for development of preeclampsia. International Journal of Current Research 2016;8(6):32519-21.

[11] Magann EF, Doherty DA, Turner K, et al. Second trimester placenta: location as a predictor of adverse pregnancy outcome. J Perinatal 2007;27(1):9-14.

[12] ACOG Committee on Obstetric Practice. Diagnosis and management of preeclampsia and eclampsia. Practice Bulletin no. 33, January 2002, American College of Obstetricians and Gynaecologists. Int J Gynaecol Obstet 2002;77(1):67-75.

[13] Khan KS, Wojdyla D, Say L, et al. WHO analysis of causes of maternal death: a systematic review. Lancet 2006;367(9516):1066-74.

[14] Zeeman GG, Cunningham FG, Pritchard JA. The magnitude of hemoconcentration with eclampsia. Hypertens Pregnancy 2009;28(2):127-37.

[15] Volhard F. Die doppelseitigen haematogenen Nierenerkrankungen. Berlin: Springer 1918.

[16] Gigee W, Raab W, Schroeder G, et al. Vascular reactivity and electrolytes in normal and toxemic pregnancy: pathogenic considerations and a diagnostic pre-toxemia test. J Clin Endocrinol Metab 1956;16(9):1196-216. 